Bangladesh Journal of Neuroscience 2015; Vol. 31 (2): 83-93

\title{
Epilepsy Patients in Bangladesh - The Experience of a Referral Hospital
}

\author{
ABDUS SALAM ${ }^{1}$, MD. RAFIQUL ISLAM ${ }^{2}$, HASAN ZAHIDUR RAHMAN ${ }^{3}$ \\ ANIS AHMED ${ }^{4}$, MD. RUHUL QUDDUS ${ }^{5}$
}

\begin{abstract}
:
Purpose: To analyze the socio-demographic and electro-clinical data of Epilepsy patients presenting in the 'Epilepsy Clinic' of a referral hospital. Method: Epilepsy patients came to this weekly clinic after referral from this hospital OPD, other hospitals and from private practitioners. All the patients were enrolled from November, 2012 to December, 2015. Then clinical diagnosis was established by the chief investigator. Routine EEG was done. MRI was advised in appropriate cases. Finally the clinical findings and investigation reports were correlated. Results: Among 331 patients, 63\% were male and $37 \%$ were female. $86 \%$ patients were in the younger age group $10-$ 29years). $75 \%$ patients were suffering from various forms of $L R E, 19 \%$ from Generalized Epilepsy Syndrome, 2.7\% were unclassified and 2.7\% had pseudo-seizure. Total 224 EEG could be done. Among them 118 (52.7\%) had different types of abnormalities. Among total 158 MRI, 120 (76\%) were abnormal. 6.3\% patients could not go to school, $3.3 \%$ left study and $12.7 \%$ patients remain unemployed due to the disease burden. Conclusion: This is a hospital based study. In this study LRE comprises $75 \%$ of total patients which is relatively higher than other reports. Males were predominating and younger people were affected more with epilepsy. Due to this disease various social problems were occurring regarding study and employment. This result demands community based larger study in our country.
\end{abstract}

Introduction:

Epilepsy is the commonest neurological condition affecting people of all ages, race and social class. There are an estimated 50 million people with epilepsy in the world, of whom up to $75 \%$ live in resource-poor countries with little to or no access to medical services or treatment ${ }^{1,2}$.

Epilepsy is clinically similar in developing and developed countries, but the extent to which patients with epilepsy are recognized, investigated, and managed is different. Epidemiology, etiology, sociocultural, and economic factors all contribute to these differences ${ }^{3}$.

Diagnostic accuracy is a particular problem in epilepsy as seizures are a symptom of diverse underlying cerebral etiologies and usually do not have any physical manifestations. Consequently a definitive diagnosis of epilepsy is often only made after an extended period of follow up, as evidenced in the Rochester study and the National General Practice Study of Epilepsy (NGPSE), a communitybased study of epilepsy in the United Kingdom. Moreover it has been found that $20-30 \%$ of those attending tertiary referral centers with refractory epilepsy do not in fact have epilepsy, with the most common differential diagnoses being dissociative seizures and syncope. As expected, neurologists are better at the diagnosis of epilepsy than nonspecialists (mistake rate $5.6 \%$ vs. $18.9 \%$ ), but a misdiagnosis rate of $5 \%$ should be considered as the absolute minimum ${ }^{4}$.

1. Assistant Professor, Neurology, Shaheed Sheikh Abu Naser Specialized Hospital, Khulna.

2. Professor, Neurology Department, Bangabandhu Sheikh Mujib Medical University, Dhaka.

3. Professor, Neurology Department, Bangabandhu Sheikh Mujib Medical University, Dhaka.

4. Assistant Professor, Neurology Department, Bangabandhu Sheikh Mujib Medical University, Dhaka.

5. Assistant Professor, Neurology, Shaheed Sheikh Abu Naser Specialized Hospital, Khulna. 
Many people with epilepsy may not come to medical attention, either due to ignorance or lack of awareness of the symptoms. This is particularly true of absence and minor complex partial seizures, which may only be recognized in retrospect following presentation with a generalized seizure. Indeed in one study of general practices only $20 \%$ of patients with seizures suspected the diagnosis prior to medical consultation ${ }^{4}$.

In Bangladesh epidemiological surveys confirm that seizure disorders are common. A study showing prevalence rate of 68 out of every 1000 for 'any seizure history' and 9 out of every 1000 for 'any unprovoked seizure', in children aged 2 to 9 years. However, there is very little information on the types of epilepsy or on their clinical presentations, EEG records, or clinical outcomes. These are important for planning management and for developing wider services within the country ${ }^{5}$.

Bangladesh is one of the densely populated countries in the world where infectious diseases, malnutrition and many chronic neurological disorders are quite common. Although there is no national statistics yet in the country but there are some hospital based studies that reflect to some extent the situation of epilepsy in Bangladesh. Studies in developed countries shows prevalence rate of about 5 per 1,000 populations whereas in developing countries it is higher. Men are more often affected than female and rural populations are affected more than the urban populations ${ }^{6}$. Based on the prevalence rate of 10 per 1,000 populations it is estimated that out of 160 million, there are at least 1.6-2.0 million people with epilepsy in Bangladesh ${ }^{7}$. The common ages of epileptic patients in Bangladesh are between 16 to 31 years. The etiology varies with age. Birth trauma, birth asphyxia, central nervous system infections are common in neonate and infancy whereas head trauma, brain tumor, stroke, infections are common causes in middle aged and elderly. Vast majority of the people in Bangladesh does have superstitious belief about Epilepsy. This belief usually is a strong barrier for total care of patients with epilepsy. Misunderstanding and negative attitude of the parents, family members and society towards epilepsy are still prevalent. Thus, many patients with epilepsy are still neglected in diagnosis, treatment, education, rehabilitation and other social needs. The epilepsy patients are often reluctant to seek advice from physicians. Rather they believe epilepsy has no cure and they seek advice from indigenous medicine practitioner 'Kabiraj', snake charmer 'Ojha' and spiritual healers. A report of 130 patients from the epilepsy clinic of BSMMU (a government postgraduate medical center) showed that close to $70 \%$ of patients visited indigenous medicine practitioners, exorcists, spiritualists prior to consulting the clinic, only $29 \%$ perceived epilepsy as a disease, $50 \%$ dropped out from school (58\% of whom due to epilepsy), and $52 \%$ of patients had to change job because of epilepsy. Appropriate antiepileptic drugs are sometime unavailable in Bangladesh. The BSMMU study showed $23 \%$ of patients found it difficult to continue treatment due to financial problem. Financial factor is likely to partly accounts for the drug non-compliance ${ }^{7}$.

The aim of our study was to obtain a baseline profile of epilepsies, to determine the types of epilepsies and epileptic syndromes in patients attending the outdoor epilepsy clinic in a tertiary care hospital and to compare the data with other centers of this country and rest of the world.

\section{Materials and Methods:}

This is an observational study carried out from records in weekly Epilepsy outdoor clinic of Department of Neurology, Shaheed Sheikh Abu Naser Specialized Hospital, Khulna (a government specialized hospital) from November 2012 to December, 2015. This is the only center in this division (comprising 10 districts and 15,563,000 inhabitants) ${ }^{8}$ which is providing such type of facilities. So patients are referred from all over the division. They are consulted free of cost. During this period a total of 331 patients with history of seizure disorder attended the clinic. All patients who had been seen consecutively in the epilepsy clinic were retrospectively enrolled into this study. There is a case record proforma for every patient attending the clinic which contains all relevant information and findings. A preformed questionnaire was used containing information on age, sex, habitat, clinical history from patients and observers, examination findings, previous and current medications, result 
of EEG and imaging studies for data collection from hospital records. A review of baseline clinical information, EEG reports, other investigations, and follow-up records was performed. If the information was insufficient, a further follow-up review was undertaken by recalling the patients and the caregivers by telephone calls ${ }^{9}$.

EEG: An EEG is advised routinely to all patients. EEG was performed at either first presentation or at any stage during the follow-up period. The EEG was obtained with a 32-channel digital machine with the electrodes placed in accordance with the International 10-20 system. In most cases recordings were obtained in both the awake and sleep states for 30-40 minutes. Photic stimulation and hyperventilation were routinely done. The EEGs were interpreted and reported by the chief investigator.

The findings were grouped into two main categories: 'normal' and 'abnormal'. The abnormal EEG was defined as the presence of interictal or ictal epileptiform discharges and/or the presence of background abnormal activity with focal or generalized, excessive slow waves or excessive fast waves, abnormal for the age and state of the patients noted during the recording. The abnormal was further classified as FED (Focal Epileptiform Discharge), GED (Generalized Epileptiform Discharge) and Others (Focal or generalized slowing, multi-focal epileptiform discharge with burst attenuation pattern). EEG abnormalities were considered focal if there was a localized spike or sharp wave discharge or focal slowing present.

Other investigations like 'MRI of Brain' was advised for all patients clinically diagnosed as suffering from LRE, symptomatic generalized epilepsy, most patients with late onset epilepsy and also for patients with clustered seizures, frequent seizures, isolated seizures, intractable epilepsy, and patients who had unexplained break-through seizures in otherwise well-controlled epilepsies. Routinely CT scan was not advised. But patients presenting with a CT done previously were documented. The available films were interpreted jointly by the radiologist and the investigator (as there is no epilepsy expert radiologist in this institute). All clearly abnormal focal lesions (e.g., tumour, infarct, gliosis, atrophy) revealed on $\mathrm{CT}$ and magnetic resonance imaging (MRI) scans of the brain were documented.

Diagnosis and classification of epilepsy: Epilepsy was diagnosed when there was a history of two or more unprovoked seizures. These were classified with a simplified International League Against Epilepsy classification (ILAE 1989, 1993) ${ }^{10,11}$ as: (a) generalized epilepsy, which included myoclonic seizures, infantile spasms, absence seizures, atonic seizures, generalized tonic-clonic seizures, generalized clonic seizures, or tonic seizures; (b) partial epilepsy, which included simple or complex partial seizures, or secondarily generalized seizures; and (c) unclassifiable seizures, which were atypical or those in which the children were not sure whether their seizure were focal or generalized in presentation ${ }^{10-13}$.

By using standard clinical and investigation criterions (ILAE 1989, 1993) epilepsy was further classified as 'symptomatic' if there was a clear antecedent history (e.g., significant head trauma, CNS infection) and when a structural lesion was documented on neuroimaging and 'idiopathic' if there was no such evidence of a cerebral lesion. Patients with recurrent seizures, and with clinical or EEG evidence of focal onset but no evidence of causation were included under 'cryptogenic' localization related epilepsy. Epileptic disorders with mental retardation and frequent seizures which lacked the characteristic features of the defined syndromes were included under "other symptomatic generalized epilepsies not defined" 10, 11 .

Partial seizures were further sub-classified chiefly on the basis of whether or not consciousness was impaired during the attack and whether or not progression to generalized convulsions occurred.

A. Simple partial seizures (when consciousness not impaired).

B. Complex partial seizures (when consciousness was impaired).

C. Partial seizures (simple or complex) evolving to secondarily generalized (tonic-clonic or tonic or clonic) seizures. 
Complex partial seizures were further sub-classified chiefly on the basis of involvement of temporal lobe or not:

1) Complex partial seizures-Temporal (CPS-T)

2) Complex partial seizures-Extra-Temporal (CPSET)

Temporal lobe epilepsy was diagnosed if the history, seizure semiology, EEG and/or imaging showed evidence in favor of seizure originating over the temporal lobes. Rest of the CPS cases which did not fit to temporal lobe origin or showed evidence of origin over other parts of brain, were considered to be CPS Extra-Temporal (CPS-ET).

As in the International League Against Epilepsy classification (ILAE 1989, 1993) there is no special entity for 'Status Epilepticus' or 'Epilepsia Partialis Continua'(EPS), the cases of EPC have been included in the partial seizure group. As all the patients were referred to this 'Epilepsy Clinic' by various physicians, the patients whose history were not convincing enough to fit for seizure, were considered to be suffering from 'Pseudo-Seizure' and the data was included in the study so that the real picture of our patients come to light.

Result:

These were 331 patients were included in this study and out of them 123(37.166) were female and $208(62.84 \%)$ were male. The majority of patients attending outdoor clinic were $<30$ years age group $(86 \%)$ (Table-I). There was a male $(62.8 \%)$ predominance (Table-II). A large number of patients were student $(35 \%)$, followed by preschool child $(14.8 \%)$ (Table-III).

Table-I

Age distribution of patients ( $n=331$ )

\begin{tabular}{lcc}
\hline Age Group & Number of Patient & Percentage \\
\hline $0-9$ yrs & 99 & 29.9 \\
$10-19$ yrs & 123 & 37.2 \\
$20-29$ yrs & 62 & 18.7 \\
$30-39$ yrs & 22 & 6.7 \\
$40-49$ yrs & 17 & 5.1 \\
$>50$ yrs & 08 & 2.4 \\
\hline Total & 331 & 100.0 \\
\hline
\end{tabular}

Table-II

Sex distribution of patients $(n=331)$

\begin{tabular}{lll}
\hline Male & 208 & 62.84 \\
Female & 123 & 37.16 \\
\hline Total & 331 & 100.0 \\
\hline
\end{tabular}

Table-III

Sex distribution of patients $(n=331)$

Occupation of Number of Patient Percentage the patients

\begin{tabular}{lcc}
\hline Non-school & 21 & 6.3 \\
Pre-school & 49 & 14.8 \\
Left school & 11 & 3.3 \\
Student & 116 & 35.0 \\
House wife & 31 & 9.4 \\
Business & 15 & 4.5 \\
Service & 19 & 5.8 \\
Unemployed & 42 & 12.7 \\
Others & 27 & 8.2 \\
\hline Total & 331 & 100.0 \\
\hline
\end{tabular}

Table-IV

Types of Seizure \& their distribution $(n=331)$

\begin{tabular}{lcc}
\hline Seizure Type & Frequency & Percentage \\
\hline LRE & 249 & 75.3 \\
Gen. Epilepsy & 64 & 19.3 \\
Unclassified & 08 & 2.4 \\
Pseudo-Sz & 09 & 2.7 \\
Total & 331 & 100.0 \\
Findings & Frequency & Percentage \\
Normal & 106 & 47.3 \\
FED & 79 & 35.3 \\
GED & 22 & 9.8 \\
Others & 17 & 7.6 \\
\hline Total & 224 & 100.0 \\
\hline
\end{tabular}


Table-V

Distribution of occupation of patients ( $n=331)$

\begin{tabular}{lcc}
\hline Seizure Type & Frequency & Percentage \\
\hline Focal Motor Seizure & 5 & 1.5 \\
CPS-T & 112 & 33.8 \\
CPS-ET & 27 & 8.2 \\
Partial Seizure with & 102 & 30.8 \\
secondary generalization & & \\
EPC & 2 & 0.6 \\
BRE & 1 & 0.3 \\
Symptomatic Generalized & 39 & 11.8 \\
Epilepsy & & \\
Sturge Weber Syndrome & 1 & 0.3 \\
Tuberous Sclerosis & 2 & 0.6 \\
Complex & & \\
IGE & 13 & 3.9 \\
CAE & 4 & 1.2 \\
JME & 3 & 0.9 \\
JAE & 1 & 0.3 \\
Gelastic Seizure & 1 & 0.3 \\
SSPE & 1 & 0.3 \\
Unclassified & 8 & 2.4 \\
Pseudo-Seizure & 9 & 2.7 \\
Total & 331 & 99.9 \\
(Reflex seizure) & 5 & \\
\hline
\end{tabular}

Table-VI

EEG findings of the patients

\begin{tabular}{lcc}
\hline Findings & Frequency & Percentage \\
\hline Normal & 38 & 24 \\
Abnormal & 120 & 76 \\
\hline Total & 158 & 100 \\
\hline
\end{tabular}

Table-VII

CT scan findings of the patients

\begin{tabular}{lcc}
\hline Findings & Frequency & Percentage \\
\hline Normal & 106 & 47.3 \\
FED & 79 & 35.3 \\
GED & 22 & 9.8 \\
Others & 17 & 7.6 \\
\hline Total & 224 & 100.0 \\
\hline
\end{tabular}

Table-VIII

MRI findings of the patients

\begin{tabular}{lcc}
\hline Findings & Frequency & Percentage \\
\hline Normal & 6 & 27.3 \\
Abnormal & 16 & 72.7 \\
\hline Total & 22 & 100.0 \\
\hline
\end{tabular}

Among the 331 patients, $75 \%$ had been suffering from various forms of localization related epilepsy (LRE), 19\% from generalized epilepsy, 2.4\% were unclassified and $2.7 \%$ from pseudo-seizure (TableV). $11.8 \%$ patients had been suffering from symptomatic generalized epilepsy (most of them were child and had history of perinatal asphyxia and head injury), 2 patients were found to have Tuberous sclerosis complex, 1 patient was found to have Sturge Weber syndrome and 1 patient was diagnosed as SSPE and 3.9\% patients had IGE (Table-VI). Five patients were identified to have reflex seizures. The seizures were precipitated by eating, sound and light. But these patients have primary features suggestive to be included in other classifications of epilepsy like CPS-T, CPS-ET and IGE (Table-VI). So they are not showed in the main sub-groups of epilepsy. EEG could be done in 224 patients. Of them 35.3\% showed FED, 9.8\% showed GED, 7.6\% showed focal or generalized slowing or multi-focal epileptiform discharge with burst attenuation pattern and $47.3 \%$ were normal (Table-6). Among total $158 \mathrm{MRI}, 76 \%$ showed various types of abnormal findings and among total 22 CT Scan $72.7 \%$ were abnormal (Table-VII, VIII).

In figure 1, a young patient of 14 years presented with the history of 'Partial Seizure with secondary generalization'. He had been suffering from 'Ventricular Septal defect with Reverse Shunt'. His EEG shows Focal Epileptiform Discharge (FED) over right frontocentro-temporal region. His MRI shows abscess over the same area of brain. Figure 2 shows 2 cases of Temporal Lobe Epilepsy, 'a' shows FED over left anterior temporal (CPS-T-Lt.) and 'b' shows FED over right posterior temporal area (CPS-T-Rt.). In figure 3, the patient presented with Simple Partial SeizureLeft sided. His EEG was normal, MRI showing 
tuberculoma over right parietal area. Figure 4 patient presented with the features of Cerebral Palsy and Complex Partial Seizure - Extra-Temporal. His EEG shows FED over left posterior head region. MRI also shows gliosis over the same area with left sided cerebral atrophy. The patient in figure 5 presented with CPS. He had mental retardation and adenoma sebaceum. He was diagnosed as Tuberous Sclerosis with CPS. His CT scan of brain shows tubers. The patient in figure 6 presented with repeated drop attacks, poor mental condition. His EEG shows runs of spike and slow wave discharge at $1-1.5 \mathrm{~Hz}$ (Status of Atypical Absence Seizure). His MRI showing bilateral gliosis (Rt.>Lt.) with right sided cerebral atrophy. These features are consistent with Symptomatic- LGS. In figure 7 the EEG of 13 month child showing multi-focal Epileptiform discharge with burst attenuation pattern which is suggestive of Epileptic Encephalopathy. In figure 8 a child of 8 years showing Spike and wave discharge at $3 \mathrm{~Hz}$ during which she was unresponsive which is a classical feature of Absence Seizure.

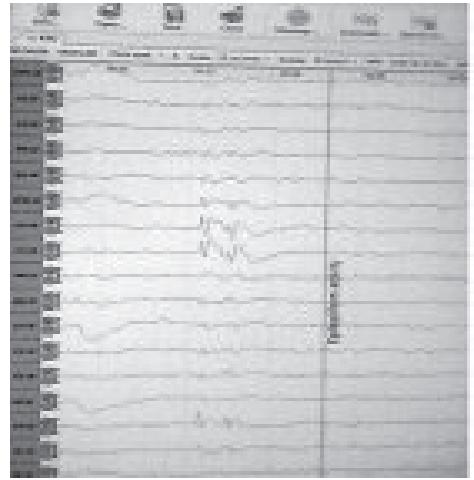

A

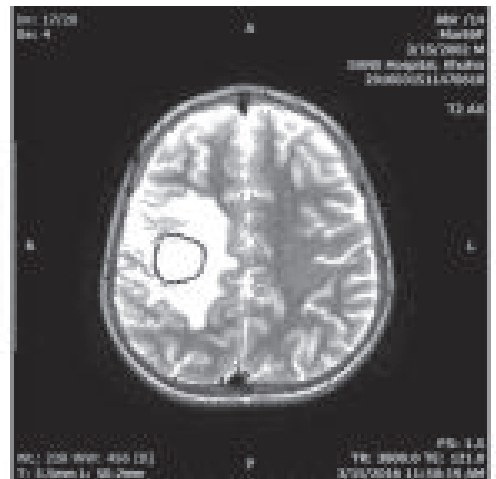

B

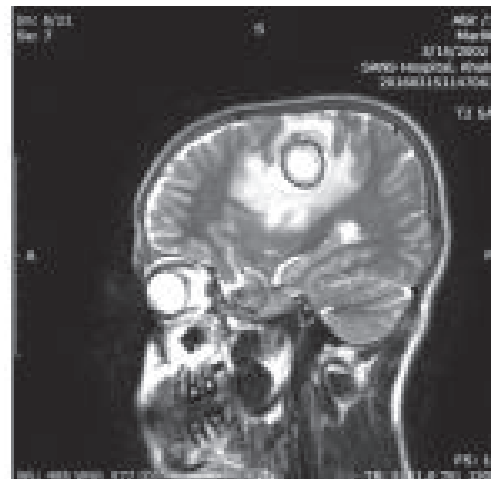

$\mathrm{C}$

Fig.-1: Abir, 14y: A-EEG - FED-Rt-Fronto-Centro-Temporal, B-MRI (b-Axial, c-sagital view) = Brain Abscess over right frontal lobe

DIAGNOSIS = Partial Sz. with secondary generalization due to Brain Abscess + VSD with reverse shunt.

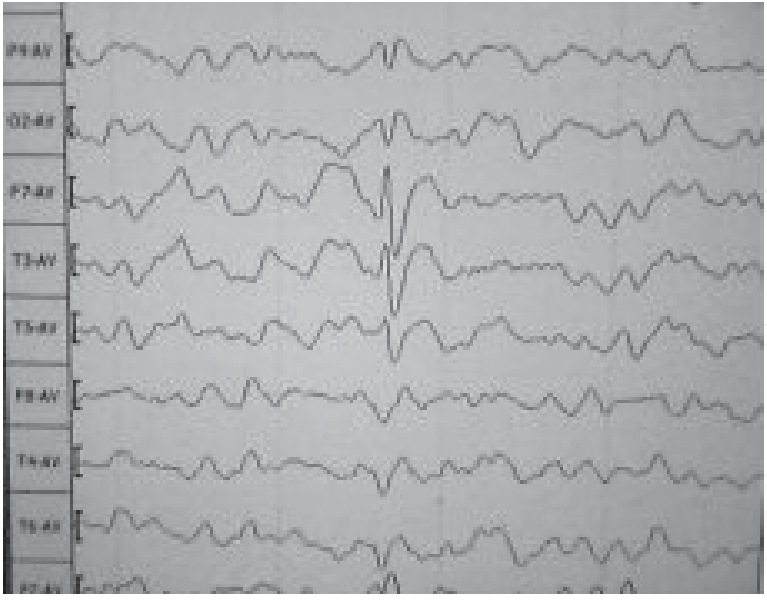

A

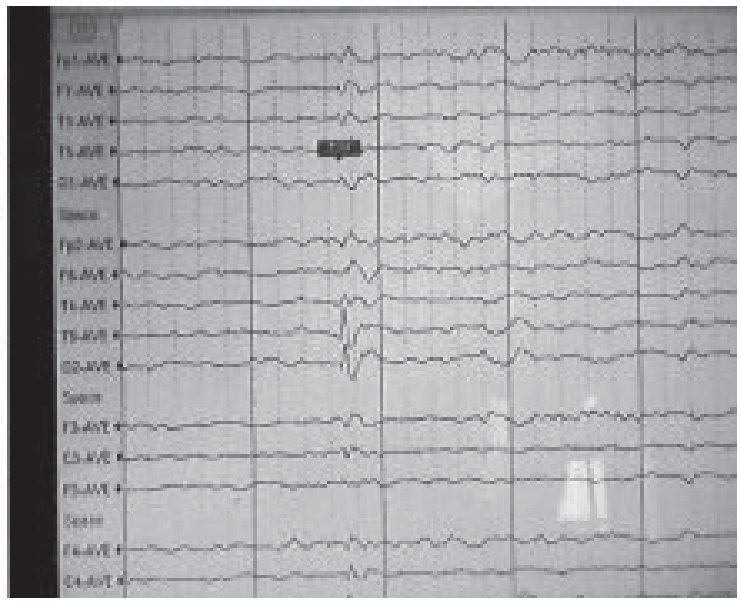

B

Fig.-2: EEG of Temporal Lobe Epilepsy. a = Left Anterior Temporal Spike, $b=$ Right Posterior Temporal Spike 


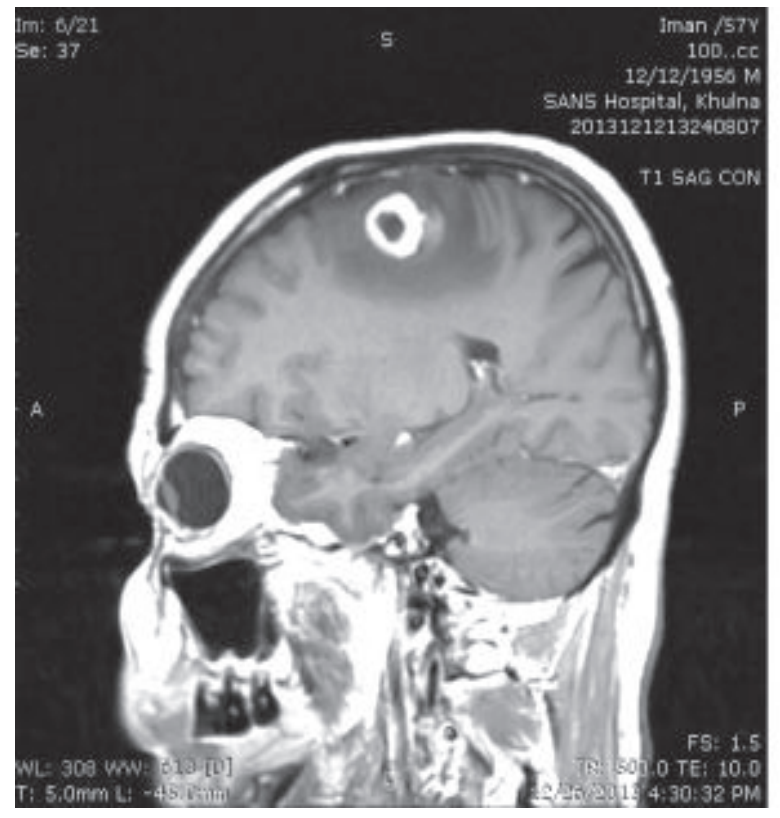

A

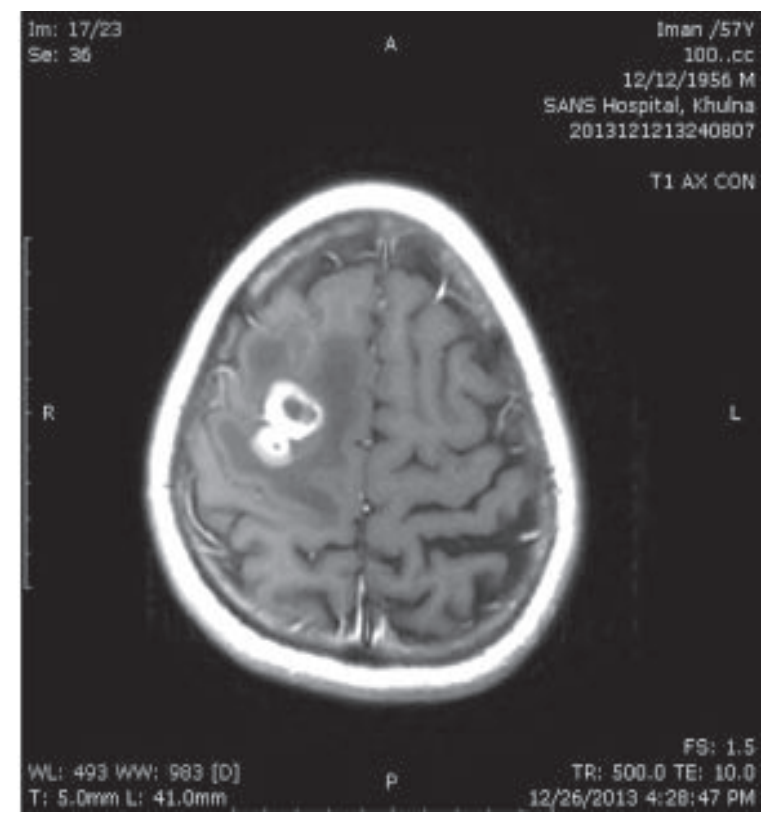

B

Fig.-3: Iman, 57Y - MRI of Brain (a-Sagital, b-Axial view) = Tuberculoma Diagnosis $=$ Simple Partial Seizure due to CNS-TB

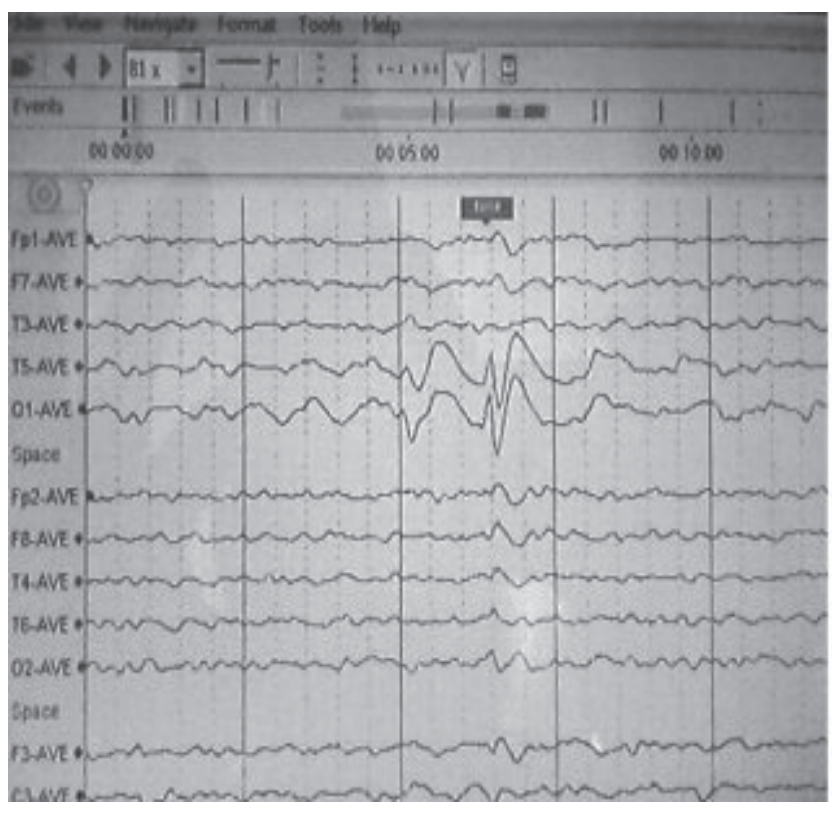

A

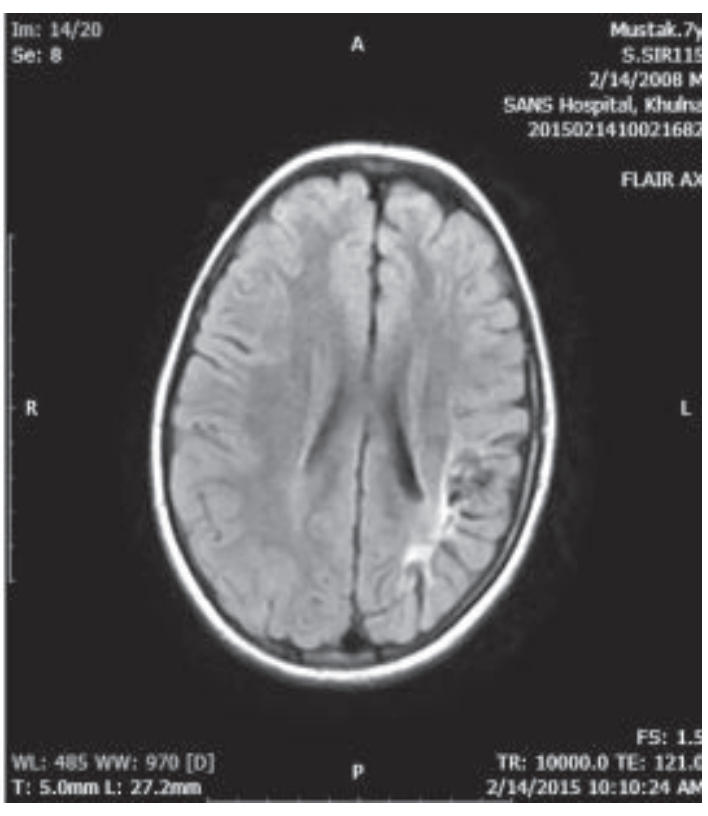

B

Fig.-4: Mustak, 7y a) EEG = Focal Epileptiform Discharge over left posterior head region with delta slowing b) MRI of Brain = Gliosis \& Atrophy (Left Parieto-Occipital) Diagnosis $=$ Cerebral Palsy + Complex Partial Seizure-Posterior Head Region 


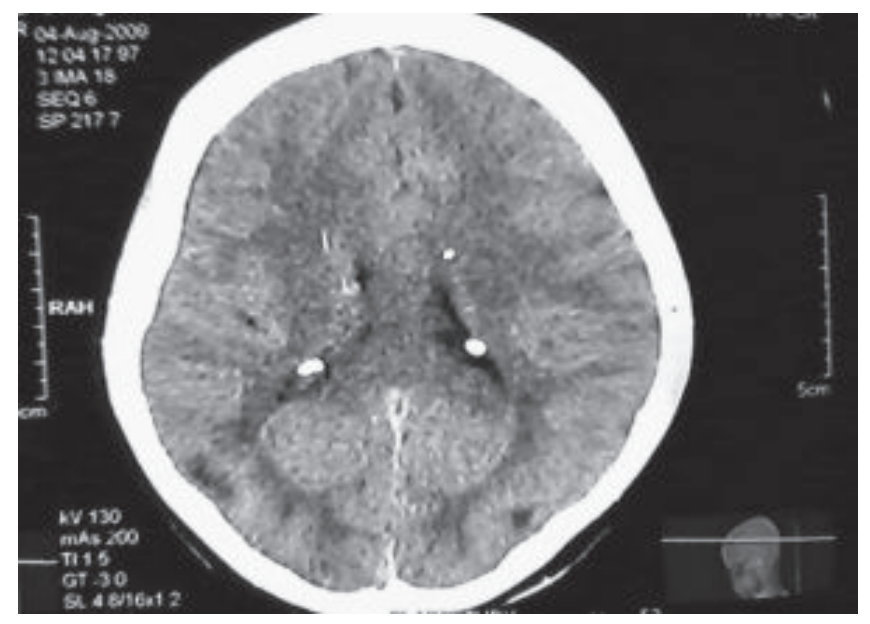

Fig.-5: CT Scan of Head (Tubers): Mominul, 18Y Diagnosis = Complex Partial Seizure due to Tuberous Sclerosis Complex
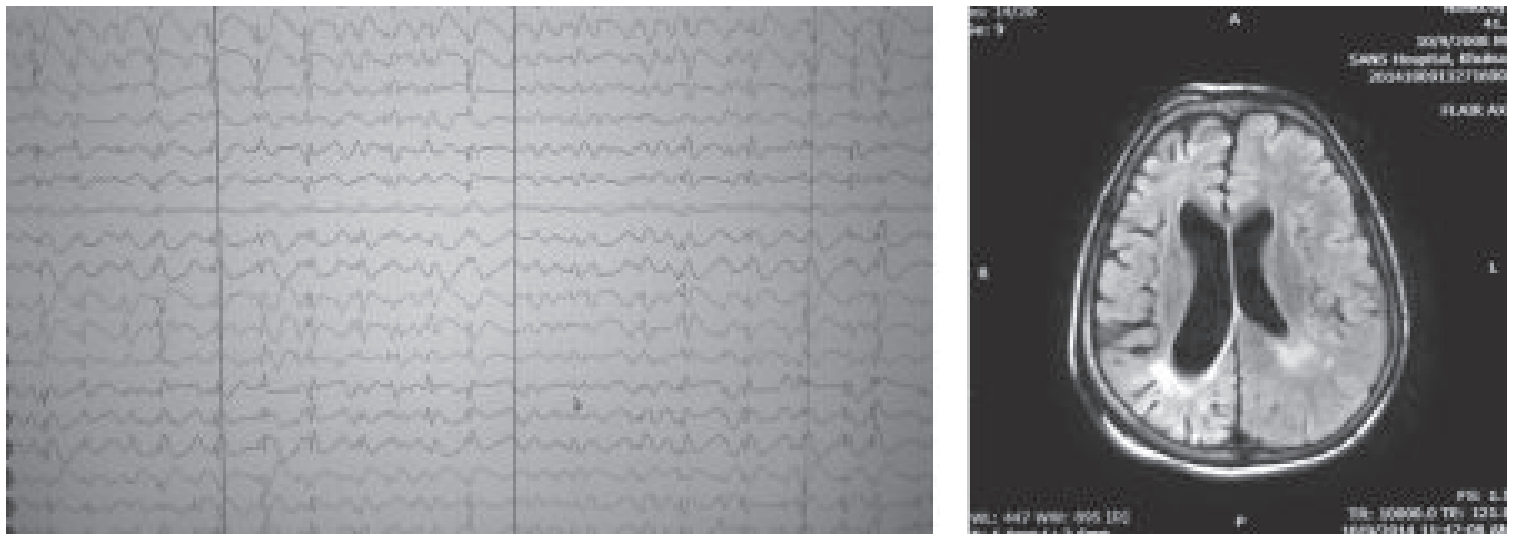

Fig.-6: Nahid, 6y: a) EEG= Atypical Absence Seizure (Status). b) MRI of Brain=Bilateral gliosis (Rt. $>$ Lt.) \& Right Cerebral Atrophy; sequele of Encephalitis at age 4y. Diagnosis = Lennox-Gastaut Syndrome

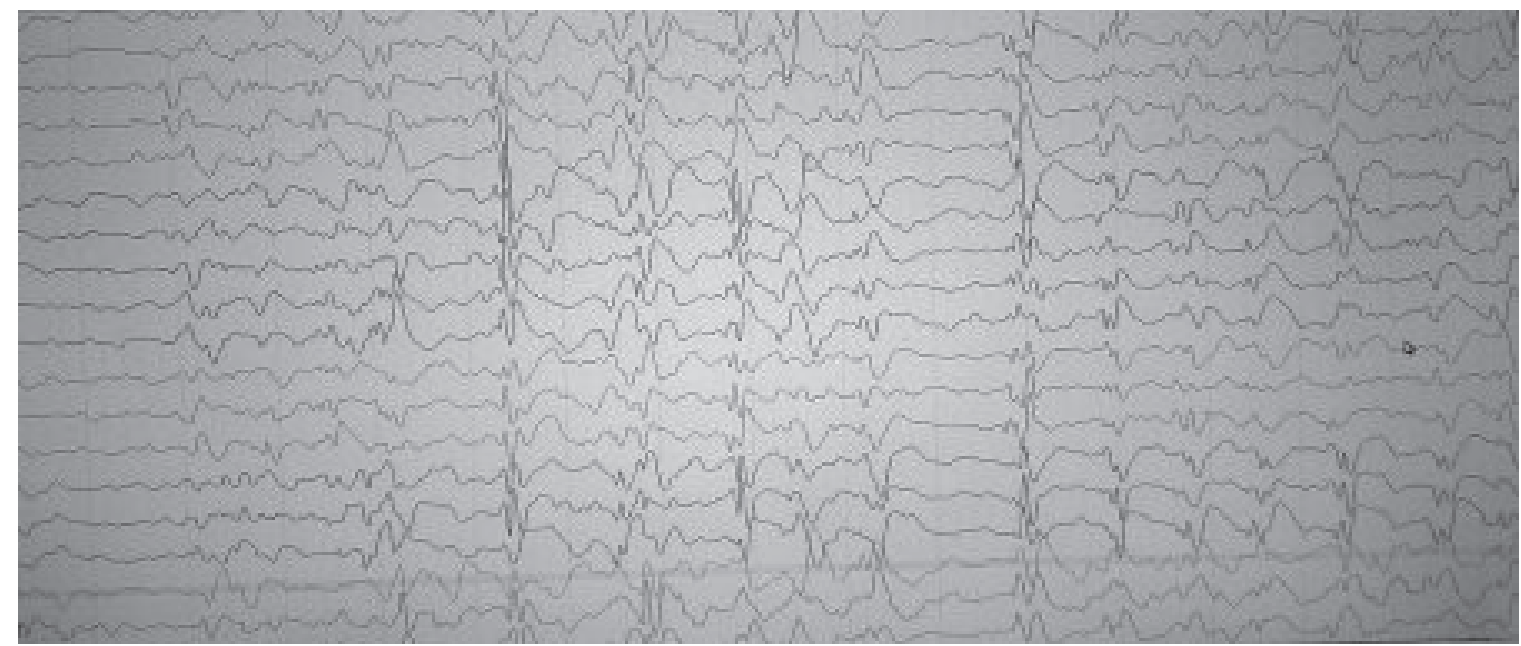

Fig.-7: Siam,13m - Multi-focal epileptiform discharge with Burst Attanuation pattern Diagnosis = Symptomatic Generalized Epilepsy with Epileptic Encephalopathy 


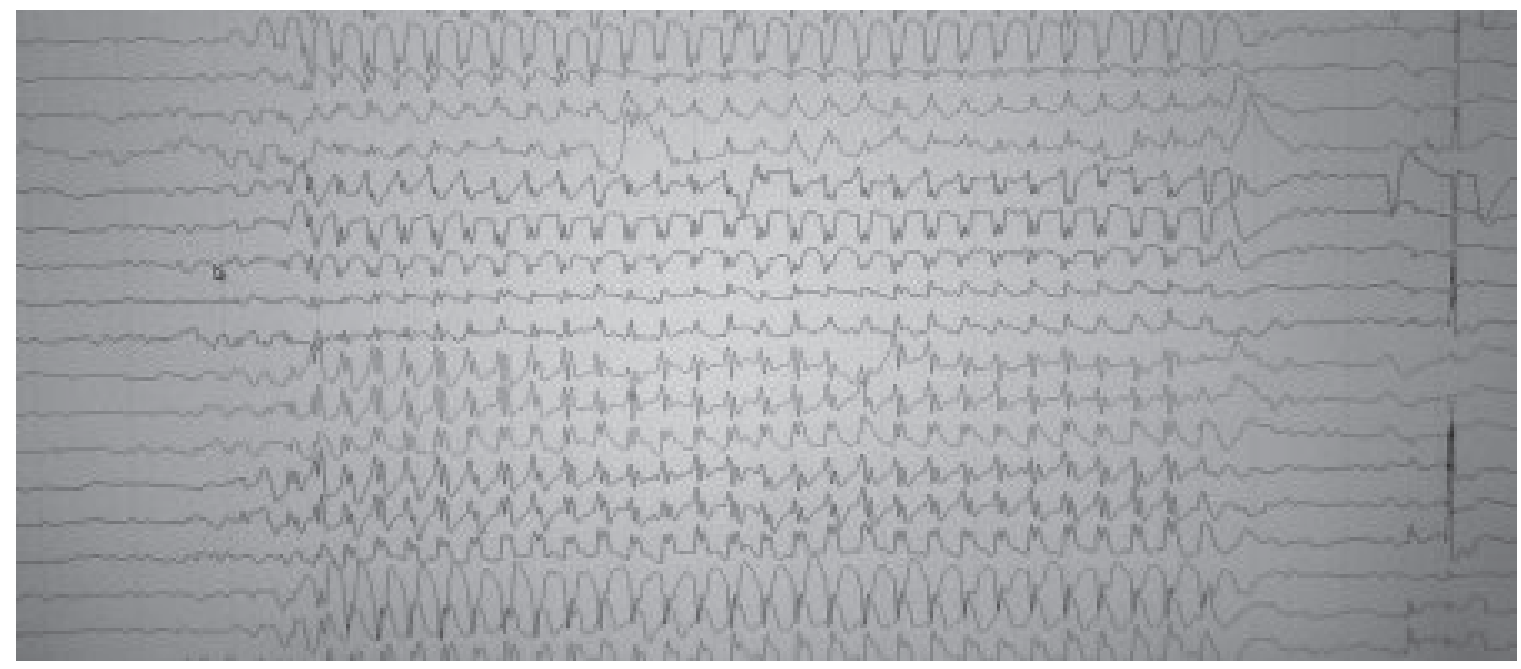

Fig.-8: Khadiza, 8y: EEG= Generalized Spike and dome discharge at $3 \mathrm{~Hz}$ (Absence Sz.)

\section{Discussion:}

Based on the findings of this study several issues demand attraction. The most common age of presentation of epilepsy was $<30$ years $(86 \%)$. In a study done by Sridharan and Murthy ${ }^{14}$, similar findings was seen; 'age-specific prevalence rates were higher in the younger age group, with the onset of epilepsy reported mostly in the first three decades of the sample population's lives'. Except for Shanghai in China, most of the Asian countries have younger epileptic patients. The probable reason for the missing peak in the older age group in many Asian countries is due to the fact that the population in general is younger ${ }^{15}$.

Here a male predominant $(62.84 \%$ ) picture is seen. Epilepsy is slightly more common in men than in women but the sex-specific prevalence is not, in general, significantly different. ${ }^{15}$ Reports are similar in other Asian countries ${ }^{16}$. Although our country has almost same socio-economic condition like the surrounding countries (India and Pakistan) here women are more home bound and neglected. Regarding epilepsy various social stigma remains. So people try to hide the illness of their daughters and sisters. As males are more exposed to outer world, their diseases come to the attention easily and people bring them to doctors. Also, as they are the earning members, their illness gets more importance for the uninterrupted continuation of earning source.
The students (35\%) came to epilepsy clinic as they are the knowledgeable group of society who has an easy access to a tertiary health care system. They draw attention through their teachers and fellows and also the parents are more concerned with the illness of their kids.

Regarding distribution of seizures $75.3 \%$ patients are suffering from various forms of LRE. Studies from India also recorded a high frequency of partial epilepsies: $62.9 \%,{ }^{17}$ and $57 \%{ }^{18}$. Data in other developing ${ }^{19-22}$ and developed countries shows same finding ${ }^{23}$. Earlier study of Bangladesh also showed a high frequency of partial epilepsies: $54 \%^{24}$.

In this study Partial seizure with Secondary generalization comprises $41 \%$ which appears to be relatively more than other's findings. These patients usually present with convulsion and draw attention of the attendants and physicians early. Many patients showed lesions (gliosis, atrophy in MRI) in occipital and posterior head region which indicates birth injury, asphyxia and trauma which may be the reason for increased number of these patients in this area.

Although few patients were ultimately diagnosed as having pseudo-seizure, this issue should be taken into account as all of them were getting antiepileptic drugs along with all the restrictions and burden of epilepsy. 
EEG findings were positive in almost $52.7 \%$ cases. This also matches with the findings of other authors $^{25}$.

There are some limitations in the study. We could not apply the recent ILAE proposal for classification of epilepsy syndrome. The study from hospital records may not completely represent the scenario in the community. Finally, also due to the retrospective nature, some aspects like the attitude of patients and attendants to epilepsy, the real burden of the disease on the family and society could not be evaluated.

\section{Conclusion:}

This study highlights some facts. Localization Related Epilepsy are more common in our country. Facilities should be improved to identify the etiology and provide extra care to reduce the burden. This is a hospital based study. Males are predominating and younger people are affected more with epilepsy. Due to the disease various social problems are occurring regarding study and employment. This result demands community based larger study in our country.

Declarations:

Funding: This research project was not funded by any group or any institution.

Ethics: The study protocol was approved by institutional ethical committee of Shaheed Sheikh Abu Naser Specialized Hospital, Khulna, Bangladesh

Data Sharing: There is no other unpublished data to share.

Conflict of interest: There is no conflict of interest relevan $1 \mathrm{t}$ to this paper to disclose.
Abbreviation :
BRE = Benign Rolandic Epilepsy
BSMMU = Bangabandhu Sheikh Mujib Medical University
$\mathrm{CAE}=$ Childhood Absence Epilepsy
CPS $=$ Complex Partial Seizure
EPC $=$ Epilepsia Partialis Continua
FED $=$ Focal Epileptiform Discharge
GED $=$ Generalized Epileptiform Discharge
IGE = Idiopathic Generalized Epilepsy

JAE = Juvenile Absence Epilepsy

JME = Juvenile Myoclonic Epilepsy

LGS= Lennox Gastaut Syndrome

LRE = Localization Related Epilepsy

OPD = Out Patient Department

$\mathrm{PHR}=$ Posterior Head Region

SSPE $=$ Sub-acute Sclerosing Pan Encephalitis

\section{References:}

1. Meinardi H, Scott RA, Reis R, Sander JW. The treatment gap in epilepsy: the current situation and ways forward. Epilepsia 2001; 42: 136-49.

2. Ngugi AK, Bottemley C, Kleinschmidt I et al. Estimation of the burden of active and life-time epilepsy: a meta-analytic approach. Epilepsia 2010; 51: 883-90.

3. Bharucha NE, Epidemiology of Epilepsy in India, Epilepsia, 2003.44(Suppl. 1):9-11

4. Neligan A and Sander JW, The incidence and prevalence of epilepsy, J Curr Opin Neurol, 2011.

5. Banu S, Khan N, Hossain M, Jahan A, Parveen $\mathrm{M}$, Rahman N, et al. Profile of childhood epilepsy in Bangladesh. Dev Med Child Neurol. 2003;45:477-82.

6. Mannan MA, Epilepsy in Bangladesh. Neurology Asia 2004; 9 (Supplement 1): 18.

7. WHO report on Epilepsy in South East Asia. Some facts and figures in Epilepsy. Available from: www.searo.who.int/LinkFiles/ Information_and_Documents_facts.

8. Bangladesh Bureau of Statistics (BBS), Report 2011.

9. Commission on Epidemiology and Prognosis, International League Against Epilepsy. Guidelines for epidemiologic studies on epilepsy. Epilepsia 1993; 34:592-6.

10. ILAE - Commission on Classification and Terminology of International League Against Epilepsy: proposal for revised classification of epilepsies and epileptic syndrome. Epilepsia. 1989;30: 389-99. 
11. ILAE - Commission on Epidemiology and Prognosis of the ILAE. Guidelines for epidemiologic studies on epilepsy. Epilepsia 1093;34: 592-6.

12. Osservatorio Regionale per L'Epilepsia (OREp), Lombardy - ILAE classification of epilepsies: its applicability and practical value of different diagnostic categories. Epilepsia 1996;37: 1051-9.

13. Beilmann A, Talvik T. Is the ILAE classification of epileptic syndromes applicable for children in Estonia? Eur J Paediatr Neurol 1999;3: 265-2.

14. Sridharan R, Murthy BN. Prevalence and pattern of epilepsy in India. Epilepsia. V;40(5): 631-6.

15. Mac T, Tran D, Quet F, Odermatt P, Preux $P$, Tan C. Epidemiology, aetiology, and clinical management of epilepsy in Asia: a systematic review. Lancet Neurol. 2007;6:533-43.

16. Fong G, Mak W, Cheng T, Chan K, Fong J, Ho S. A prevalence study of epilepsy in Hong Kong. Hong Kong Med J. 2003;9:252-7.

17. Murthy JMK, Yangala R and Srinivas M. The Syndromic Classification of the International League Against Epilepsy: A Hospital-Based Study from South India, Epilepsia, 1998 ;39(1):48-54
18. Mani KS, Rangan G. Epilepsy in the Third World: Asian aspects. In: Dam M, Gram L, eds. Comprehensive epileptology. New York: Raven Press, 1090;pp: 781-93.

19. Matuja WBP. Aetiological factors in Tanzanian epileptics. East Afr Med J. 1989;66:343-8.

20. Danesi MA. Classification of the epilepsies: an investigation of 945 patients in a developing country. Epilepsia. 1985;26(13): 1-6.

21. Senanayake N. Classification of epileptic seizures: a hospitalbased study of 1,250 patients in a developing country. Epilepsia. 1993;34(8): 12-8.

22. Tan CT, Lim SH. Epilepsy in South East Asia. Neurol J Southeast Asia. 2: 11-15. 1997.

23. Zarrelli MM, Beghi E, Rocca WA, Hauser WA. Incidence of epileptic syndromes in Rochester, Minnesota: 1980-1984. Epilepsia. 1999;40(12):1708-14.

24. Khan SU et.al; Characteristics of epilepsy patients at a tertiary care hospital in Bangladesh, Research. 2014;1:74.

25. Smith SJM. EEG in the diagnosis, classification, and management of patients with epilepsy, J Neurol Neurosurg Psychiatry 72014;76:2-7. 